Book Chapter

\title{
Electrical Resistivity Tomography as a Support Tool for Physicochemical Properties Assessment of Near-Surface Waste Materials in a Mining Tailing Pond (El Gorguel, SE Spain)
}

María Gabarrón ${ }^{1}$, Pedro Martínez-Pagán ${ }^{2} *$, Marcos A MartínezSegura $^{2}$, María C Bueso ${ }^{3}$, Silvia Martínez-Martínez ${ }^{1}$, Ángel Faz ${ }^{1}$ and José A Acosta ${ }^{1}$

${ }^{1}$ Sustainable Use, Management and Reclamation of Soil and Water Research Group, Escuela Técnica Superior de Ingeniería Agronómica, Universidad Politécnica de Cartagena, Spain

${ }^{2}$ Department of Mining and Civil Engineering, Universidad Politécnica de Cartagena, Spain

${ }^{3}$ Department of Applied Mathematics and Statistics, Universidad Politécnica de Cartagena, Spain

*Corresponding Author: Pedro Martínez-Pagán, Department of Mining and Civil Engineering, Universidad Politécnica de Cartagena, Paseo Alfonso XIII, 52, 30203 Cartagena, Spain

Published December 28, 2020

This Book Chapter is a republication of an article published by Pedro Martínez-Pagán, et al. at Minerals in June 2020. (Gabarrón, M.; Martínez-Pagán, P.; Martínez-Segura, M.A.; Bueso, M.C.; Martínez-Martínez, S.; Faz, Á.; Acosta, J.A. Electrical Resistivity Tomography as a Support Tool for Physicochemical Properties Assessment of Near-Surface Waste Materials in a Mining Tailing Pond (El Gorguel, SE Spain). Minerals 2020, 10, 559.)

How to cite this book chapter: María Gabarrón, Pedro Martínez-Pagán, Marcos A Martínez-Segura, María C Bueso, Silvia Martínez-Martínez, Ángel Faz, José A Acosta. Electrical 
Resistivity Tomography as a Support Tool for Physicochemical Properties Assessment of Near-Surface Waste Materials in a Mining Tailing Pond (El Gorguel, SE Spain). In: Arkady Kalinin, editor. Minerals: Technology and Advances. Hyderabad, India: Vide Leaf. 2020.

(C) The Author(s) 2020. This article is distributed under the terms of the Creative Commons Attribution 4.0 International License(http://creativecommons.org/licenses/by/4.0/), which permits unrestricted use, distribution, and reproduction in any medium, provided the original work is properly cited.

Acknowledgments: In memory of Joselito M. Arocena, University of Prince George, Canada. Thank you for your support, wherever you are.

\section{Abstract}

Legacy mining industry has left a large number of tailing ponds in the Cartagena-La Union mining district exposed to water and wind erosion, which causes serious environmental and health problems and requires remediation. Before applying any remediation technique, an intensive sampling of the materials infilling the pond is required to determine the geochemistry of the pond, which will condition the remediation process. However, sampling the large number of tailing ponds that compose the district could be expensive. Thus, the main objective of this study is to evaluate the usefulness of electrical resistivity tomography (ERT) as a non-invasive tool to provide an image of spatial subsurface resistivity distribution and its relation to the physicochemical composition of near-surface mine wastes. To achieve this objective, three short ERT profiles were conducted, and 12 samples in each profile were collected at different depths for its geochemical characterization. Several non-linear regression models were fitted to predict physicochemical properties and metal concentrations from electrical resistivity measures. As a result, a high resistivity area was depicted in the ERT profiles G2 and G3, while the low resistivity ERT profile G1 was also obtained in accordance with the site's surficial characteristics. Relationships among low 
resistivity values and high salinity, clay content, high metal concentrations, and mobility were established. Specifically, calibrated models were obtained for electrical conductivity, particles sizes of 0.02-50 $\mu \mathrm{m}$ and 50-2000 $\mu \mathrm{m}$, total $\mathrm{Zn}$ and $\mathrm{Cd}$ concentration, and bioavailable $\mathrm{Ni}, \mathrm{Cd}$, and $\mathrm{Fe}$. The ERT technique was shown to be a useful tool for the approximation of the location and distribution of the highest ranges of fine particle sizes, moisture, and, to a lesser extent, metal accumulation in the near-surface waste materials.

\section{Keywords}

ERT Method; Heavy Metal; Regression Model; Remediation; Tailing Pond

\section{Introduction}

The mining of metalliferous mineral deposits and associated smelting and metal processing activities have led to perturbations in surface environments [1]. Indeed, metal-based ore processing generates a large amount of mine tailings, which are watery sludge composed of medium- to fine-size-grain material [2]. Due to natural leaching from these reactive materials, contamination of the environment close to the deposits often occurs [3]. In the Cartagena-La Union mining district (SE Spain), the legacy of more than 2500 years of intensive mining activity has left a large number of tailing ponds that generate environmental impacts due to leachates with high concentrations of sulphides and metallic elements [1,4-7]. Their wastes are characterized by significant amounts of metals such as $\mathrm{Pb}, \mathrm{Zn}, \mathrm{Cu}$, and $\mathrm{Cd}$, high salinity, acidic $\mathrm{pH}$ levels, and low soil organic matter content [8]. Therefore, mining pond characteristics make the natural establishment of vegetation difficult. In fact, tailing ponds are waste storage structures with bare surfaces completely exposed to erosion agents that promote the transport of those contaminants to the surrounding areas [9]. It has been demonstrated that plant cover provides physical protection to minimize wind erosion and the surface runoff of soil materials [10]. 
To appropriately implement phytostabilization techniques, a precise and representative physicochemical characterization of the tailing ponds, required to collect a high, representative number of samples from these ponds, is required, not only from the surface but also underneath by means of core sampling acquisition tools or mechanical drilling rigs [6]. However, to accomplish this adequate physicochemical characterization through conventional sampling techniques such as boreholes, auger drilling, and superficial sampling grids, a high budget and time-consuming work are required [11,12]. Therefore, it would be interesting to minimize those drawbacks with the assistance of geophysical techniques, especially electrical resistivity tomography (ERT), since there have been revolutionary improvements in the resistivity method in recent years, and twodimensional (2-D) surveys are now routinely conducted in many study fields [13].

The electrical resistivity method is one of the oldest and most commonly used geophysical exploration methods [14]. Indeed, electrical resistivity tomography is a non-invasive technique that enables obtaining a large number of resistivity data in a short period of time, and it has been widely used in environmental and engineering [15-19], hydrological [20,21], archaeological [22,23], and mineral exploration [24-26] surveys. In addition, it has been used for image structures from the millimeter to kilometer scale [27,28].

Most of the studies carried out on tailing ponds using ERT have been focused on identifying the tailings' internal structure, defining the morphology of the tailing-bedrock contact, highlighting the occurrence of faults or cracks that could put the pond stability at risk, and/or pinpointing preferential pathways for heavy metal transport or acid mine drainage $[6,7,11,12,29,30]$. However, the use of ERT to establish relationships among electrical resistivity data and physicochemical variables such as moisture, heavy metal concentration, $\mathrm{pH}$, particle size distribution, and $\mathrm{Al} / \mathrm{Si}$ as a proxy for clay content in tailing ponds or soils severely polluted by mining has not been widely studied [6, 31]. 
In this study, we attempt to establish associations between the physicochemical properties of tailings and electrical resistivity data. We propose establishing regression models based on these relationships as a proxy to predict the areas inside the pond, and these could show the highest water retention, the finest particles, and a presence of metals, avoiding huge sampling campaigns. Regression models based on electrical resistivity data have been widely used in complex sedimentary environments to estimate water flows and soil moisture content, usually in crop soils and polluted floodplains [19,32-35]. However, the use of regression to range soil properties and metal concentrations using electrical resistivity as a reference variable is quite new $[19,35,36]$.

Therefore, the primary objective of this study is to evaluate the usefulness of ERT as a non-invasive method to derive variations in the physicochemical properties of the most surficial layers of mine tailing ponds, thus enabling more efficient phytoremediation action, representing environment-related work on former mining sites that have been severely affected.

\section{Material and Methods Study Area}

The Cartagena-La Union mining district is located in the southeast of the Murcia Province (Spain) (Figure 1). Considered one of the most ancient mining areas of Europe, it developed important industrial activity since the Roman period to the first half of the 20th century, which has caused landscape and environmental damage in the area, especially due to the accumulation of mine waste in ponds and acid mine drainages. More than 80 tailing ponds have been catalogued in the area, and a considerable number of them are characterized by high metal concentrations and similar mineral composition: quartz, magnetite, jarosite, goethite, clinochlore, and gypsum. Primary minerals in natural soils of the mining district are dolomite, kaolinite, hematite, calcite, muscovite, and anorthoclase [37]. Nevertheless, metal content and its disposal are specific to each one. 


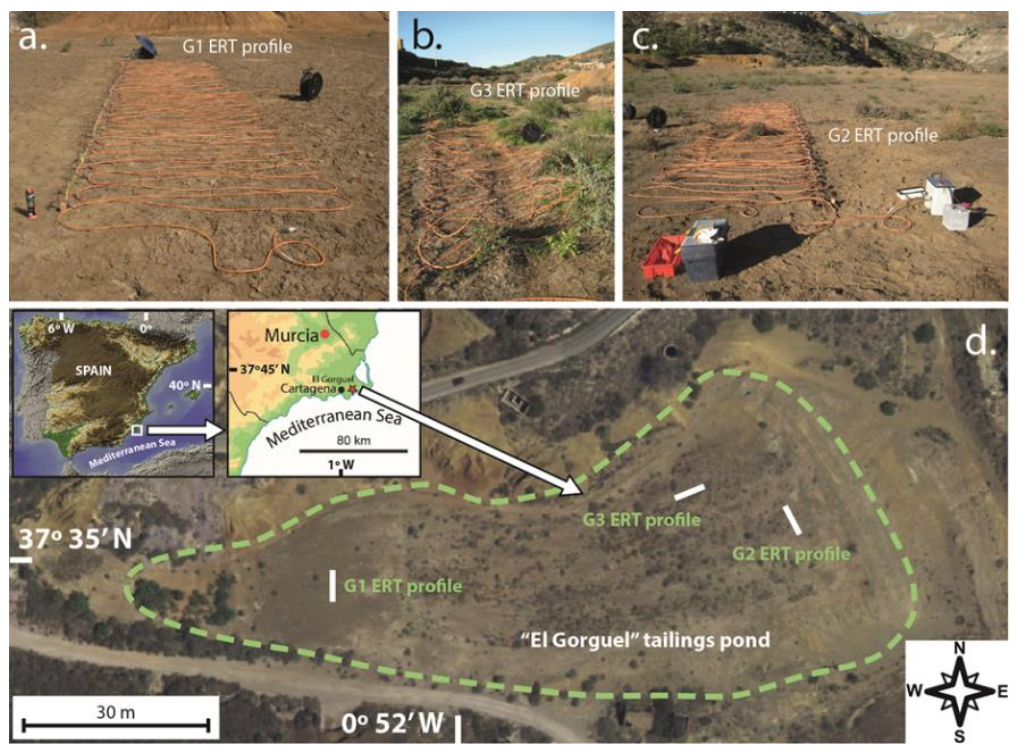

Figure 1: Location of the study area and detailed view of the ERT profile G1(a), G2 (b), and G3 (c) and their position on the tailing pond (d).

The climate of the area is semiarid Mediterranean, characterized by an annual average temperature of $18{ }^{\circ} \mathrm{C}$ and an annual precipitation of $290 \mathrm{~mm}$ [38]. This study is focused on the El Gorguel tailing pond $\left(37^{\circ} 35^{\prime} \mathrm{N}, 0^{\circ} 52^{\prime} \mathrm{W}\right)$, which presents an area of $7.4 \mathrm{~km}^{2}$, a $14 \mathrm{~m}$ depth, and a $150,000 \mathrm{~m}^{3}$ volume [4]. It was considered representative of the acidic type of tailing ponds located in the Cartagena-La Union mining district because it had a similar range of salinity, a lack of vegetation and metal content, low organic matter, and similar mineralogy, and was more affected by water and wind erosion than other tailing ponds in the area $[39,4]$. In September 2011, a remediation project was carried out, amending the mining wastes with marble sludge and pig slurry in a rate of $4 \mathrm{~kg} / \mathrm{m}^{2}$ and $3 \mathrm{l} / \mathrm{m}^{2}$, respectively (European Commission Framework Project FP7 IRIS) [40].

The studied tailing pond, like other tailing ponds in this mining district, was formed in the first half of the 20th century as a result of the disposal of mine waste generated from mineral processing of $\mathrm{Fe}-\mathrm{Pb}$ - and $\mathrm{Zn}$-based sulphide ores. Ponds were formed by the gravitational accumulation of waste materials discharged 
from wooden sluices with multiple outlets (Figure 2). Water in the tailings was drained through either a decant outlet situated in the center or drainage pipes installed on the perimeter of the pond. Due to gravity, the configuration of the ponds led to the settling of heavy and coarse particles close to the dam, while light and fine materials were concentrated near the water disposal points. As in many mining areas in the world, when a tailing pond was full, another dam was constructed upstream, leading to a series of dams (Figure 2) $[41,42]$.

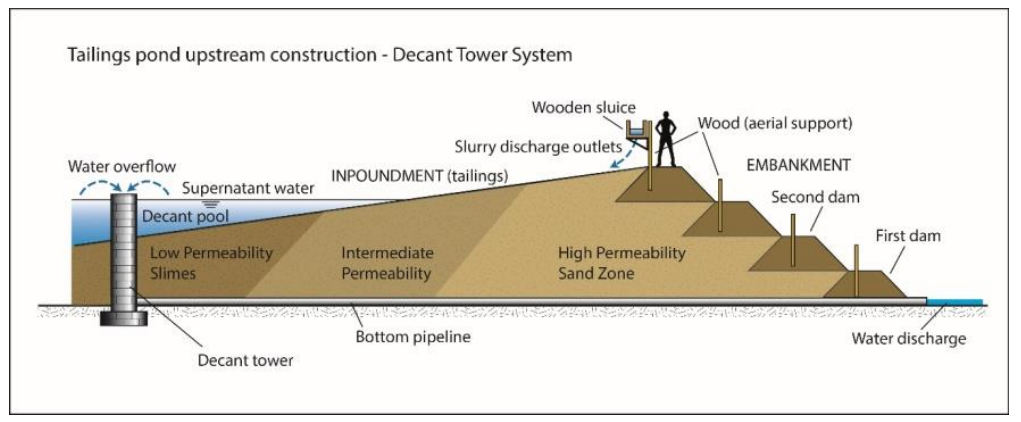

Figure 2: Tailing pond from staged embankment. Tailing segregation zones and soil characteristic as a function of distance from the spilling location [41].

\section{Electrical resistivity tomography (ERT)}

Electrical resistivity tomography (ERT) was employed as a primary geophysical technique. ERT is suitable for investigating complex subsurface structures with vertical and lateral resistivity changes [18], whose resistivity values, depending on the particular site conditions, are influenced by the variation of important properties of the ground such as moisture, soil salinization, and particle size distribution, of which moisture is considered by far the most influential [43].

Three short ERT profiles were laid out on the tailing pond to accurately characterize the tailing pond surface to a depth of about $1 \mathrm{~m}$, which is the most crucial layer in remediation or phytostabilization work (Figure 1). Figure 3 depicts the El Gorguel tailing pond, where three ERT profiles are located across the tailing pond and a fourth ERT profile following a 
lengthwise orientation were conducted as part of a European Commission Framework Project [40]. These ERT profiles identified two different surficial tailing areas according to their electrical resistivity values. Thus, the western side of the tailing pond was characterized by low electrical resistivity values $(<8 \Omega$ $\mathrm{m}$ ), and the eastern side of the tailing pond, close the pond embankment, was characterized by higher electrical resistivity values $(>8 \Omega \mathrm{m})$. Therefore, the orientation and position of the small ERT profiles of this study were chosen in order to locate them in these two different regions.

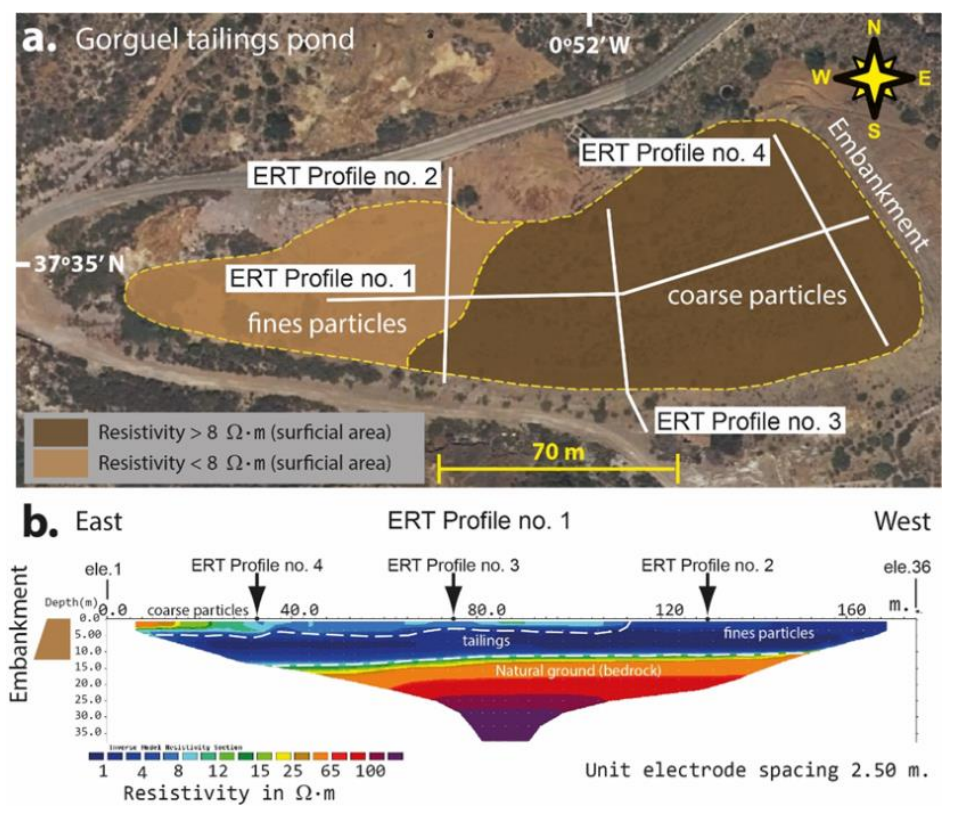

Figure 3: Different surficial zones according to their electrical resistivity values.

Apparent resistivity measurements were obtained by a Syscal R1 resistivity meter (IRIS Instruments) with 36 stainless steel electrodes laid out in a transect at constant intervals, with $30 \mathrm{~cm}$ electrode spacing and a total length of $10.5 \mathrm{~m}$. We were interested in reaching an investigation horizon of about a $1 \mathrm{~m}$ depth, since most phytoremediation studies carried out on tailing ponds of this area demonstrated that the main physicochemical variations occurred at that thickness $[37,39,40]$. In order to 
combine a good penetration depth, a reasonable vertical and horizontal resolution, the dipole-dipole array was chosen for this study $[44,45]$. This measurement array has been successfully used in similar studies [17]. The resistivity meter used an injection cycle of $1 \mathrm{~s}$ with an output voltage of up to $400 \mathrm{~V}$ and rejection filters for 50 and $60 \mathrm{~Hz}$. Noise reduction was obtained by applying continuous stacking, selectable from a minimum value of 3 to a maximum of 6 stacks. With these parameters, an average value (and its associated level of uncertainty) of the apparent resistivity was obtained for each quadripole. After the acquisition of the apparent resistivity values, the data were processed to remove bad data. This was done by filtering raw data with low signal values $\left(\mathrm{V} / \mathrm{I}<10^{-6} \Omega\right)$ or repeatability errors greater than $2 \%$. From a theoretical point of view, the depth of investigation of a measurement depends on the length of the transmitting line $\mathrm{AB}$ (current injection electrodes) and on the separation between the transmitting $\mathrm{AB}$ line and the receiving MN (potential measurement electrodes) line [46]. Thus, the maximum depth reached for dipole-dipole arrays is estimated to be $0.2 \cdot \mathrm{L}, \mathrm{L}$ being the total length of the cable [46]. In our study, $\mathrm{L}$ was $10.8 \mathrm{~m}$, so the maximum depth was $2.16 \mathrm{~m}$, which is enough to reach resistivity data levels of up to a 1.2-1.5 m depth.

The apparent resistivity datasets from each ERT profile were processed in two stages: 1) initial filtering and removing of the noisy data by means of PROSYS II software; 2) data processing through RES2DINV software [47, 48]. The code RES2DINV uses the L1 and L2 norms for the data inversion-based processing [13, 49]. The method uses a finite element scheme for solving the 2-D forward problem and the blocky inversion method for inverting the ERI data [13, 48, 49]. The 2D electrical section finally obtained was constituted by true, spatially distributed electrical resistivity data, which are related to the variation in the physicochemical properties of the tailing pond [50].

\section{Sampling collection and geochemical analysis}

Twelve soil samples were collected from each ERT profile (G1, $\mathrm{G} 2$, and G3) - 4 samples at 0-30 cm, 4 samples at 30-60 cm, and 
4 samples at $60-90 \mathrm{~cm}$ - in the El Gorguel tailing pond, for a total number of 36 soil samples, collected using a manual core and packed in plastic bags to be returned to the laboratory.

Samples were dried in a forced-air oven at $45{ }^{\circ} \mathrm{C}$ for $72 \mathrm{~h}$ and sieved through a $2 \mathrm{~mm}$ mesh for physicochemical analysis. A subsample of the sieved sample was ground with an agate mortar (RetschRM 100).

$\mathrm{pH}$ was measured in a solution of 1:2.5 soil/deionized water ratio [51], and soil electrical conductivity (S-EC) was measured in a 1:5 soil/deionized water suspension [51], both using selective electrodes. Organic carbon was determined by the dichromate method [51], and calcium carbonate was determined by the volumetric method of Bernard's calcimeter. Particle size analysis was carried using the Bouyoucos method [52].

The pseudo-total metal concentration was determined by acid digestion of $1 \mathrm{~g}$ of ground sample, with $10 \mathrm{~mL}$ of nitric acid $\left(\mathrm{HNO}_{3}\right)$ and $10 \mathrm{~mL}$ of perchloric acid $\left(\mathrm{HClO}_{4}\right)$, heated at $210{ }^{\circ} \mathrm{C}$ for $90 \mathrm{~min}$ in a heating block equipped with a temperature sensor and a time control panel to ensure digestion. To minimize loss by evaporation or volatilization, a recovery system for gases was used in the procedure. After cooling, the samples were passed through a $0.2 \mu \mathrm{m}$ filter for quantitative analysis, and $0.1 \mathrm{~N} \mathrm{HCl}$ was added to volume in a $100 \mathrm{~mL}$ volumetric flask [53]. The total amounts of metals ( $\mathrm{Zn}, \mathrm{Pb}, \mathrm{Cu}, \mathrm{Cd}, \mathrm{Cr}, \mathrm{Ni}, \mathrm{Fe}$, and $\mathrm{As}$ ) were determined by ICP-OES/MS (Agilent 7500CE).

Bioavailable metals were obtained using the Lindsay and Norvell's (1978) [54] and Crock and Severson's (1980) [55] method of adding DTPA in a 1:2 soil/DTPA ratio. After shaking, samples were filtered and measured by ICP-OES/MS (Agilent 7500CE). Water-soluble metals were obtained according to Buurman et al.'s (1996) [56] and Frau's (2000) [57] method of using a 1:5 soil/deionized water ratio. After shaking and filtering, extracts were measured by ICP-OES/MS (Agilent $7500 \mathrm{CE})$. For quality assurance, reagent blanks, as well as certified reference materials (BAM-U110), available from the Federal Institute for Materials Research and Testing Research 
and Testing, were also run with the samples. Recoveries obtained for BAM-U110 were $87 \%$ for $\mathrm{Pb}, 95 \%$ for $\mathrm{Cu}, 95 \%$ for $\mathrm{Ni}, 86 \%$ for $\mathrm{Cr}$, $89 \%$ for $\mathrm{Zn}, 97 \%$ for $\mathrm{Cd}$, and $81 \%$ for As.

\section{Statistical analysis}

The Kolmogorov-Smirnov normality test at $\mathrm{P}<0.05$ was used to ensure a normal distribution of the data. This normality assumption was rejected even after log-transformation. As a consequence, non-parametric methods were applied to the data. The Mann-Whitney $\mathrm{U}$ test at $\mathrm{P}<0.05$ was performed to assess significant differences among profiles for each variable. Spearman correlation, denoted by $\mathrm{r}_{\mathrm{s}}$, was carried out to establish relationships between electrical resistivity data and waste physicochemical properties. The significance of the correlation coefficient was tested at 0.05 level. These statistical analyses were performed with the software IBM SPSS Statistics v.23.

In this study, a simple nonlinear regression analysis was carried out to obtain a model that allowed for the prediction of waste properties and metal content in the amended tailing ponds based on electrical resistivity data. The selected-response variable (Y) was the different waste properties or metal concentration, while the waste resistivity was used as an explanatory variable for prediction (X). Boxplot graphs were used to determine outlier data that were excluded from the test. Seventy-five percent of the total data were randomly selected and used as the calibration set, while the remaining $25 \%$ was used as the validation set. Residuals from the calibrated models were satisfactorily checked for the model assumptions of normality (Kolmogorov-Smirnov test), linearity, and homoscedasticity, and fitted models with $\mathrm{R}^{2}<$ 0.6 were rejected. To validate the models, residuals from the estimated variables of the validation set should be within the confidence interval (CI) (at 95\%) of the residual distribution of the calibrated model. CI was calculated as \pm 1.96 times the standard deviation of the residuals in the calibrated model. Modeling was performed with the software SigmaPlot v.12 (Systat Software, Inc.). 


\section{Results and Discussion \\ Soil Properties, Metal Concentration, and ERT Imaging}

The $\mathrm{pH}$ in the tailing pond ranged from slightly acidic to moderately alkaline [37], because in a previous rehabilitation project, in order to neutralize the potential acid generation, experimental plots were built, and marble waste $(98 \%$ carbonates) was applied to the entire pond surface [40] [58]. Salinity (S-EC) ranged from very slightly saline to slightly saline [37] due to the coprecipitation of metallic salts with carbonates from the amendments [57]. Inorganic carbon, organic carbon, and nitrogen showed low contents (Figure 4), as were expected in these mining wastes. Coarse-size (50-2000 $\mu \mathrm{m})$ and mediumsize $(0.02-50 \mu \mathrm{m})$ particles were dominant in the mining waste particle size composition, ranging from $59 \%$ to $85 \%$ and from $8 \%$ to $43 \%$, respectively, while the fine fraction $(<2 \mu \mathrm{m})$ represents only $4-10 \%$ of the total particles.

All metal analyzed exceeded the limit established as a reference of non-polluted soils (NGR) in the Region of Murcia [59], except $\mathrm{Cr}$ and $\mathrm{Ni}$, which showed values close to the background level of the area. Therefore, total $\mathrm{Zn}$ concentration (mean of the whole pond: $8263 \mathrm{mg} \mathrm{kg}^{-1}$ ) was 92 times higher than the NGR $\left(90 \mathrm{mg} \mathrm{kg}{ }^{-1}\right)$, while $\mathrm{Pb}\left(3394 \mathrm{mg} \mathrm{kg}^{-1}\right)$ and $\mathrm{Cd}\left(123 \mathrm{mg} \mathrm{kg}^{-1}\right)$ showed values 60 and 50 times higher than their reference values (57 and $0.5 \mathrm{mg} \mathrm{kg}^{-1}$, respectively); As (350 mg kg $)$, considered one of the most toxic elements for human health [60], was over 22 times the NGR (16 mg kg$\left.{ }^{-1}\right)$. Finally, $\mathrm{Cu}$ was four-fold higher than its NGR $\left(30 \mathrm{mg} \mathrm{kg}^{-1}\right)$. Similar concentrations of $\mathrm{Zn}, \mathrm{Pb}$, and $\mathrm{Cd}$ were found in tailing ponds from the Cartagena-La Unión mining district $[11,61,62]$. 

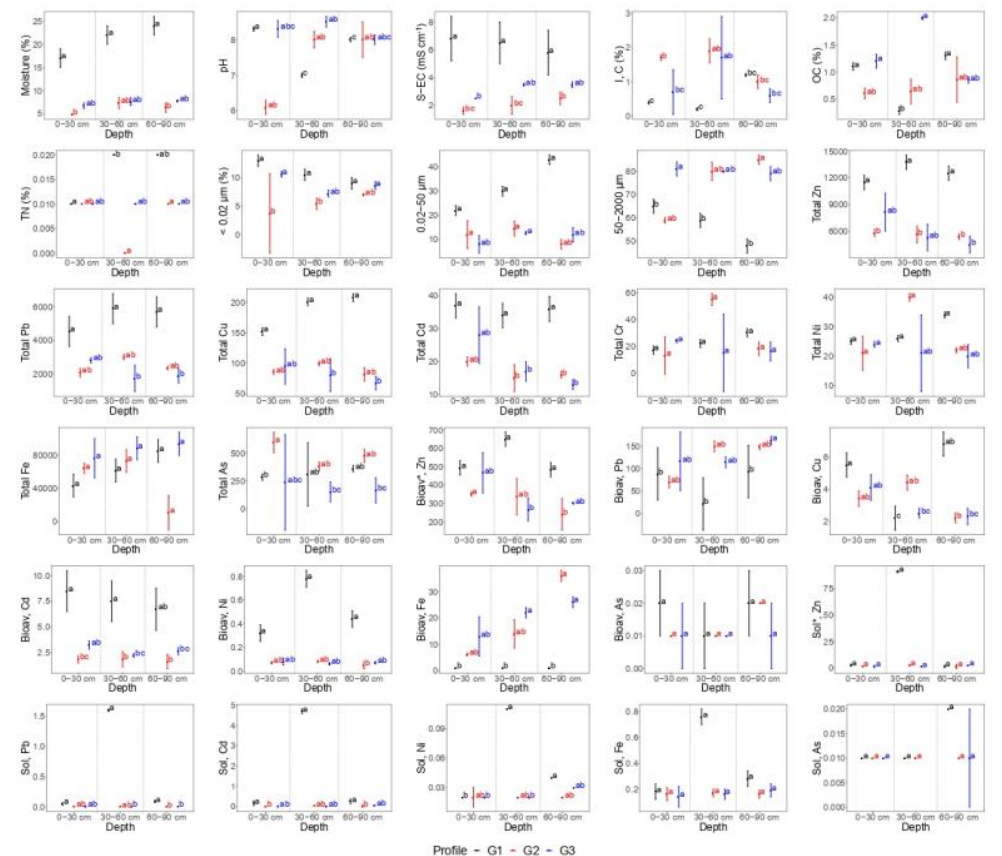

Figure 4: Soil properties, metal concentration $\left(\mathrm{mg} \mathrm{kg}^{-1}\right)$ (mean \pm standard deviation), and results from the Mann-Whitney U-test.

*Bioav.: bioavailable. Sol.: water-soluble. Bioav. Cr, Sol. Cu, and Sol. Cr showed values lower than the detection limit of the equip. Different letters in the same row indicate statistically significant differences between variables ( $P$ $<0.05)$.

About the mobility of metals, $\mathrm{Zn}$ and $\mathrm{Pb}$ had the highest concentration of bioavailable metals, although the ratio between the mean bioavailable concentration and the mean total metal concentration revealed that the most available metal was $\mathrm{Cd}$, followed by $\mathrm{Zn}, \mathrm{Pb}, \mathrm{Cu}, \mathrm{Ni}, \mathrm{Cr}$, and As. The water solubility of the metals was closed to zero, except $\mathrm{Zn}$ and $\mathrm{Cd}$, which showed slightly higher concentrations in some profiles.

The ERT survey showed great differences among the ERT profile G1 and the profiles G2 and G3 (Figure 5). In G1, the whole section showed very low resistivity values (1-4 $\Omega \mathrm{m}$ ), except in a small area located between 30 and $60 \mathrm{~cm}$ deep, where resistivity increased to $10 \Omega \mathrm{m}$ (Figure 5a). Profiles G2 and G3 
showed a more heterogeneous distribution of resistivity that allowed the depiction of different areas within each profile. Resistivity values in the main part of the G2 ranged from 25 to $90 \Omega \mathrm{m}$. However, a higher resistivity area (Region 1 ) can be discerned from the surface to a $50 \mathrm{~cm}$ depth $(>100 \Omega \mathrm{m})$ as well as a lower resistivity area (10-20 $\Omega \mathrm{m})$ on the right side of the profile (region 3) (Figure 5b).

In G3, the highest resistivity area is located between the surface and a $30 \mathrm{~cm}$ depth (Region 1), showing values that reach $90 \Omega$ $\mathrm{m}$, which was substantially in contrast with the low resistivity of the entire profile that ranges from 6 to $20 \Omega \mathrm{m}$ (Figure 5c). This high resistivity area, or Region 1, is thinner than that region of G2, in agreement with the higher moisture content in G3 compared to that of G2. This surficial higher moisture in G3 could explain, among other factors such as basic $\mathrm{pH}$ values in G3, the important, spontaneous growth of vegetation in G3 [6365].

Similar resistivity values were obtained by Martín-Crespo et al. (2018) [12] from the Brunita tailing pond (La Unión, Spain) and by Acosta et al. (2017) [66] from tailing ponds in the Mazarrón (Spain) mining district, where the same types of ore (pyrite, galena, and sphalerite) were extracted.

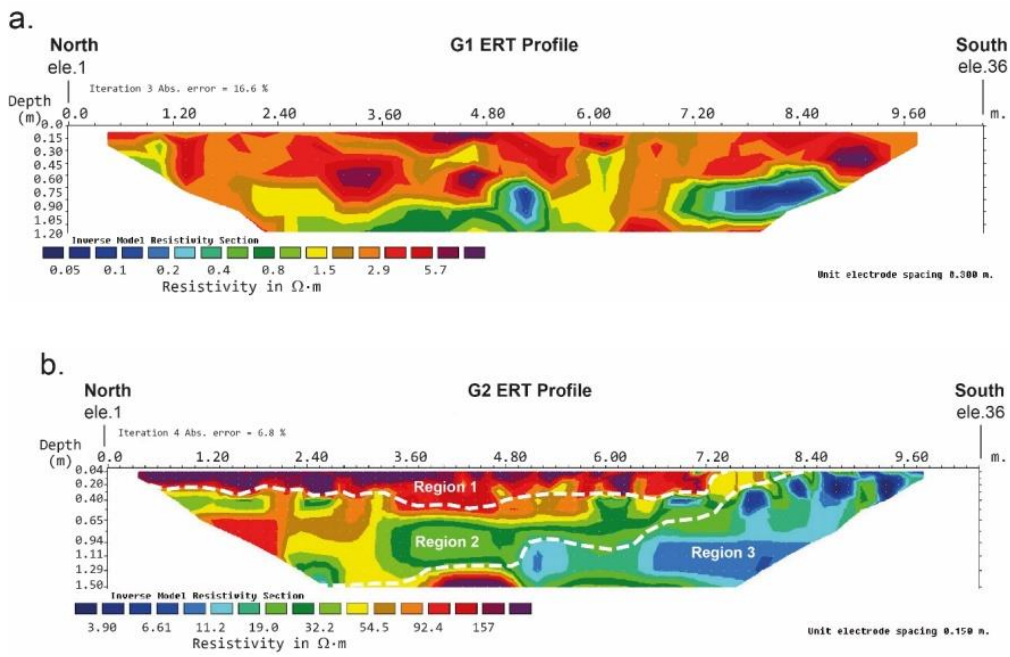




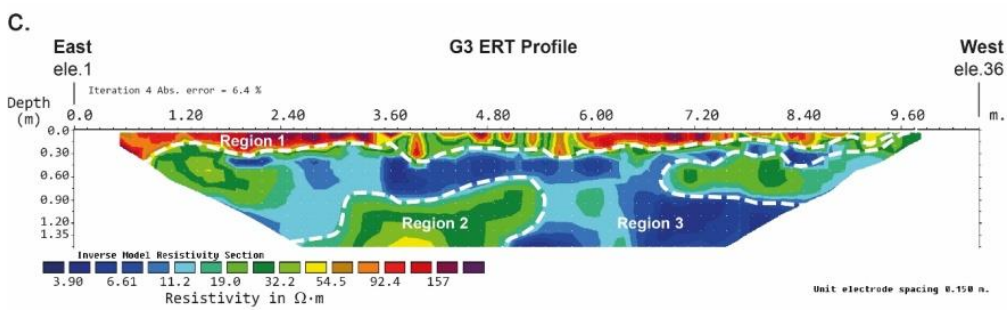

Figure 5: Electrical resistivity sections of Profiles G1 (a), G2 (b), and G3 (c).

Particle size distribution is closely related to the electrical conductivity in soils, affecting the amount of surficial electrical charges of the solid soil constituents $[67,68]$. Hence, clayed size particles, which promote the trapping of a film of electrolyte around them, contribute to a better conduction of the electricity in soils, giving lower values of resistivity than sandy or loamy soils $[14,67,68]$. It is also related to the capability of clayed size particles for better water retention. In the studied tailing pond, despite the coarse-size $(50-2000 \mu \mathrm{m})$ and medium-size $(0.02-50$ $\mu \mathrm{m})$ particles were predominant, statistically significant differences were found in G1, which showed a higher percentage of fine particles $(<0.02 \mu \mathrm{m})$ than G2 and G3 profiles (Figure 4). This was in accordance with results obtained for moisture, which showed higher values in G1. Thus, the lower resistivity values found in G1 seemed to be influenced by the higher presence of fine materials, although it was not be possible to distinguish the degree to which moisture and fine particles influence the resistivity. Regardless, the relation established for G1 between observed resistivity values and fine particle sizes was in accordance with that found by Martín-Crespo et al. (2018) [12] and Faz et al. (2013) [69], who explained that, in the CartagenaLa Unión mining district, materials that show electrical resistivities below $8 \Omega \mathrm{m}$ correspond to fine-grain tailings, while resistivities ranging from 8 to $150 \Omega \mathrm{m}$ correspond to waste rocks.

No differences were found between G1 and G2-G3 in terms of waste physicochemical properties, except for salinity and inorganic carbon content, which showed the highest content in G1. G3, at a 30-90 cm depth, showed a slightly higher content in organic carbon, total nitrogen, and particles sizes of $0.02-2000$ 
$\mu \mathrm{m}$ than G2. High organic carbon content is usually related to low bulk density in soils, increasing the aggregate stability that suppose a decrease in resistivity [75], as well as the presence of fine particles. Therefore, the differences indicated by these properties in both profiles were shown to be responsible for the lower electrical resistivity indicated by G3 at a $30-90 \mathrm{~cm}$ depth. There were no significant variations in the soil properties with depth, except in G1 where $\mathrm{pH}$ decreases in depth.

No statistical differences were found in the variation in total metal concentration with respect to depth within G1, G2, or G3. However, a comparison between profiles showed statistical differences in total $\mathrm{Zn}$ content between G1 and G2, indicating a higher $\mathrm{Zn}$ concentration in G1 compared to that in G2. For total $\mathrm{Pb}$ and $\mathrm{Cu}$, statistical differences were found between G1 (0-90 $\mathrm{cm}$ depth) and G3 (30-90 cm depth), the highest values found in G1. Cd concentration in G1 $(0-90 \mathrm{~cm}$ depth $)$ was also statistically different from that in G2 and G3 at a $30-90 \mathrm{~cm}$ depth, the highest values of total $\mathrm{Cd}$ being found in $\mathrm{G} 1$. Moreover, statistical differences were observed for total As between G1 $(0-30 \mathrm{~cm})$ and $\mathrm{G} 2(0-30 \mathrm{~cm})$, although in this case the concentration was higher in G2. Fine particle sizes can retain a large amount of metals because of their high specific surface area [70]. Thus, the highest amount of total metals found in G1 seems to be associated with the highest amount of clayed and fine lime-sized particles in G1.

Indeed, fine particles are generally more reactive than coarse ones [71], while moisture acts as the media where the mobile phase of metals such as metallic sulphates are released being capable of conducting electricity in soil. Also, the presence /absence of water in soils determine the redox process that affect mobility of metals because the adsorption/desorption processes [76]. Thus, the lowest resistivity values found in G1 primarily seemed associated with the presence of fine particles and moisture, although it could also be influenced, to a lesser extent, by the concentrations of bioavailable and soluble metals, because such metals are more prone to be solved in the pore solution under this conditions. No statistical differences were found among sampling depths in $\mathrm{G} 1$, except for $\mathrm{Cu}$, whose bioavailable 
concentration decreased at a $30-60 \mathrm{~cm}$ depth. Similar relations were observed in other tailing ponds from the Cartagena-La Unión mining district (Spain) [69], Ursk (Russia) [72], and Viljakkala (Finland) [73].

\section{ERT Model}

In order to identify associations among electrical resistivity and physicochemical parameters, a Spearman correlation test was performed. Results showed that resistivity was negative and significantly correlated with soil electrical conductivity $\left(\mathrm{r}_{\mathrm{s}}=-\right.$ 0.911; $\mathrm{P}<0.01)$, particles $<0.02 \mu \mathrm{m}\left(\mathrm{r}_{\mathrm{s}}=-0.809 ; \mathrm{P}<0.01\right)$, moisture $\left(\mathrm{r}_{\mathrm{s}}=-0.776 ; \mathrm{P}<0.01\right)$, bioavailable $\mathrm{Cd}\left(\mathrm{r}_{\mathrm{s}}=-0.713, \mathrm{P}<\right.$ $0.01)$, TN $\left(\mathrm{r}_{\mathrm{s}}=-0.696 ; \mathrm{P}<0.001\right)$, soluble $\mathrm{Pb}\left(\mathrm{r}_{\mathrm{s}}=-0.636, \mathrm{P}<\right.$ $0.01)$, soluble $\mathrm{Cd}\left(\mathrm{r}_{\mathrm{s}}=-0.636 ; \mathrm{P}<0.01\right)$, bioavailable $\mathrm{Ni}\left(\mathrm{r}_{\mathrm{s}}=-\right.$ $0.6128, \mathrm{P}<0.01)$, total $\mathrm{Zn}\left(\mathrm{r}_{\mathrm{s}}=-0.601 ; \mathrm{P}<0.01\right), 0.02-50 \mu \mathrm{m}$ particles $\left(\mathrm{r}_{\mathrm{s}}=-0.579 ; \mathrm{P}<0.01\right)$, total $\mathrm{Cu}\left(\mathrm{r}_{\mathrm{s}}=-0.578 ; \mathrm{P}<0.01\right)$, total $\mathrm{Cd}\left(\mathrm{r}_{\mathrm{s}}=-0.571 ; \mathrm{P}<0.01\right)$, total $\mathrm{Pb}\left(\mathrm{r}_{\mathrm{s}}=-0.556, \mathrm{P}<0.01\right)$, bioavailable $\mathrm{Zn}\left(\mathrm{r}_{\mathrm{s}}=-0.519 ; \mathrm{P}<0.01\right)$, soluble As $\left(\mathrm{r}_{\mathrm{s}}=-0.505, \mathrm{P}\right.$ $<0.01)$, bioavailable As $\left(\mathrm{r}_{\mathrm{s}}=-0.475 ; \mathrm{P}<0.05\right)$, and total $\mathrm{Ni}\left(\mathrm{r}_{\mathrm{s}}=\right.$ $-0.435, \mathrm{P}<0.05)$.

A negative correlation suggests that higher water content, fine and medium particle sizes, and the presence of metals, especially in its bioavailable and soluble fractions, are related to lower values of electrical resistivity $[65,73,74]$.

Resistivity was also positive and significantly correlated with 50$2000 \mu \mathrm{m}$ particles $\left(\mathrm{r}_{\mathrm{s}}=0.802 ; \mathrm{P}<0.01\right)$, bioavailable $\mathrm{Fe}\left(\mathrm{r}_{\mathrm{s}}=\right.$ $0.572, \mathrm{P}<0.01)$, bioavailable $\mathrm{Pb}\left(\mathrm{r}_{\mathrm{s}}=0.543 ; \mathrm{P}<0.05\right)$, and soluble $\mathrm{Fe}\left(\mathrm{r}_{\mathrm{s}}=0.512, \mathrm{P}<0.05\right)$, meaning that coarser grain sizes promote higher resistivity values $[14,67,68]$.

Physicochemical parameters significantly correlated with resistivity (with $\left|\mathrm{r}_{\mathrm{s}}\right|>0.5$ ) were selected, and non-linear regression models were fitted to the data. As a result, several model formulations were obtained for the different dependent variables (Figure 6): polynomial-cubic for moisture $(\mathrm{Z}=0.34 ; \mathrm{P}$ $<0.0001)$ : total $\mathrm{Zn}(\mathrm{Z}=0.664 ; \mathrm{P}<0.0001)$ and $50-2000 \mu \mathrm{m}$ particles $(Z=0.68 ; P<0.0001)$; polynomial-inverse of 3rd order 
for soluble $\mathrm{Cd}(\mathrm{Z}=0.013 ; \mathrm{P}<0.0001)$ : soil electrical conductivity $(Z=0.018 ; \mathrm{P}<0.0001)$, bioavailable $\mathrm{Ni}(\mathrm{Z}=0.033$; $\mathrm{P}<0.0001)$, bioavailable $\mathrm{Cd}(\mathrm{Z}=0.196 ; \mathrm{P}<0.0001)$, and soluble $\mathrm{Pb}(\mathrm{Z}=0.595 ; \mathrm{P}<0.0001)$; exponential decay-linear combination for total $\mathrm{Cd}(\mathrm{Z}=0.10 ; \mathrm{P}<0.0001)$ : $0.02-50 \mu \mathrm{m}$ particles $(Z=0.23 ; \mathrm{P}<0.0001)$, total $\mathrm{Pb}(\mathrm{Z}=0.34 ; \mathrm{P}<0.0001)$, total $\mathrm{Cu}(\mathrm{Z}=0.39 ; \mathrm{P}<0.0001)$, and bioavailable $\mathrm{Fe}(\mathrm{Z}=0.56 ; \mathrm{P}$ $<0.0001)$, or polynomial-quadratic for particles $<0.02 \mu \mathrm{m}(\mathrm{Z}=$ 0.013; $\mathrm{P}<0.0001$ ). Only TN, total Fe, bioavailable $\mathrm{Zn}$ and $\mathrm{Pb}$, and soluble Fe and As did not achieve all assumptions for model acceptance (residuals normality and homoscedasticity (Z), and $\mathrm{R}^{2} \geq 0.6$ ) (Figure 6).

The efficiency of each obtained model was validated by applying the corresponding model to each parameter for the validation set. This validation is shown in Figure $\mathrm{S} 1$ by plotting the real value of the studied parameter measured in the field and the value estimated with the model validation samples $(n=9)$.

The best fitting of estimated data was obtained for soil electrical conductivity and bioavailable $\mathrm{Cd}$, with $89 \%$ of the estimated data within the confidence interval (CI) at 95\%. Seventy-eight percent of the estimated data for $0.02-50 \mu \mathrm{m}$ and $50-2000 \mu \mathrm{m}$ particles, total $\mathrm{Zn}$, total $\mathrm{Cd}$, and bioavailable $\mathrm{Ni}$ and $\mathrm{Fe}$ were within CI, verifying the high quality of the models obtained for these parameters. However, the efficiency of the models obtained for soluble $\mathrm{Cd}$, total $\mathrm{Pb}$, total $\mathrm{Cu},<0.02 \mu \mathrm{m}$ particles, and soluble $\mathrm{Pb}$ was constrained because only $67 \%, 56 \%, 33 \%$, $22 \%$, and $1 \%$, respectively, of the estimated data were located within the CI. This methodology was similar to that used by other authors [32,34,36], who also faced estimated and real moisture data in plots as well as metals [19]. 
Minerals: Technology and Advances
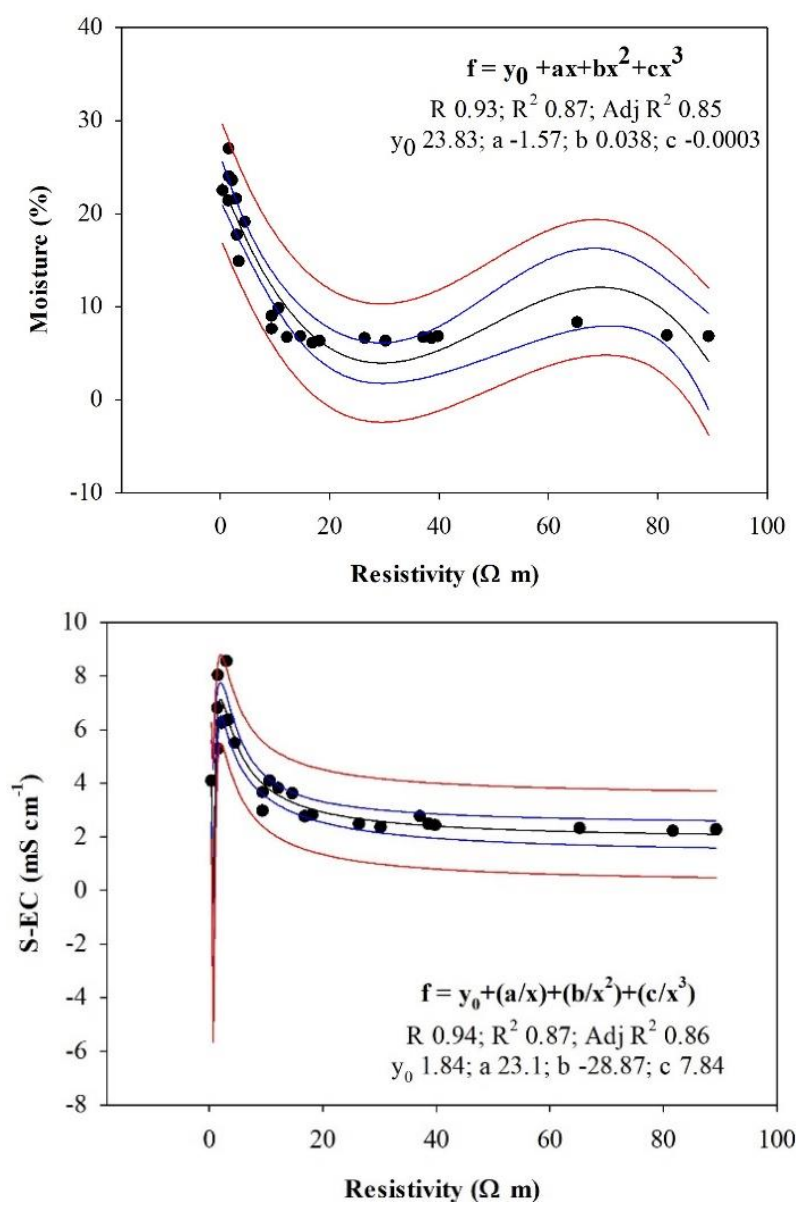
Minerals: Technology and Advances
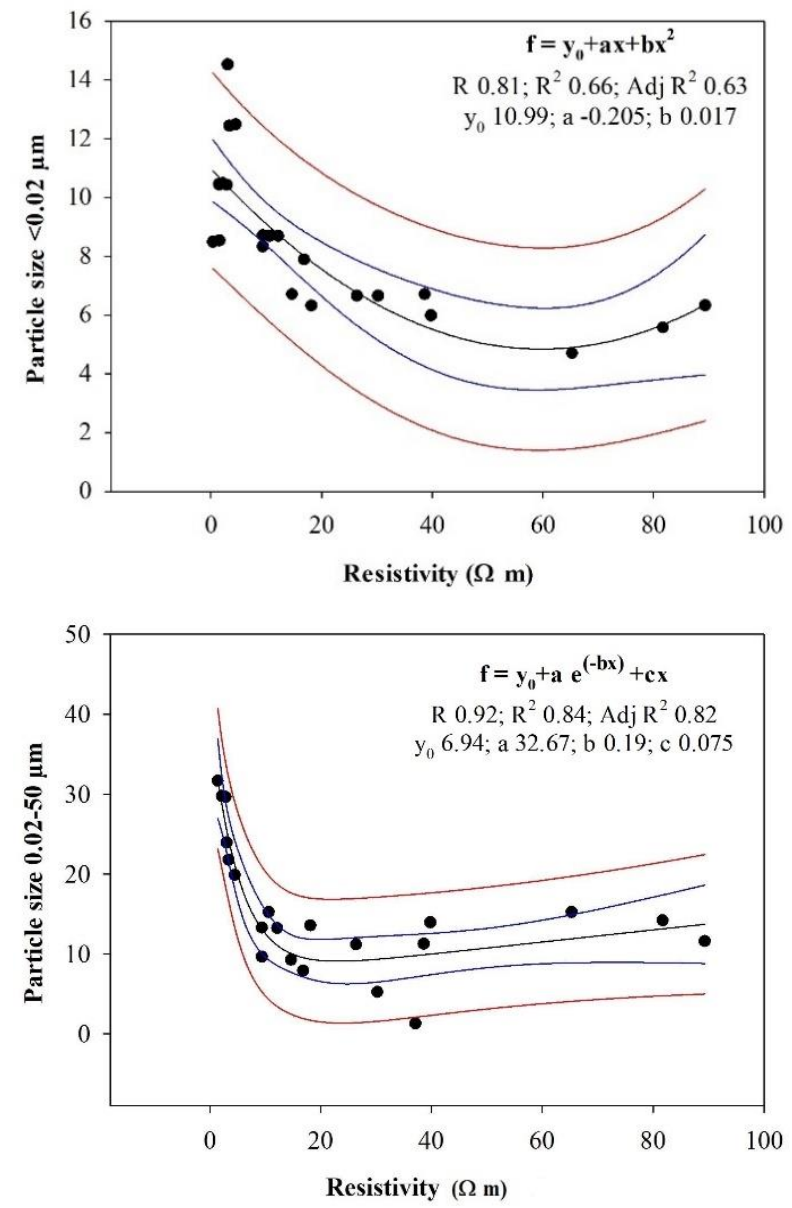
Minerals: Technology and Advances
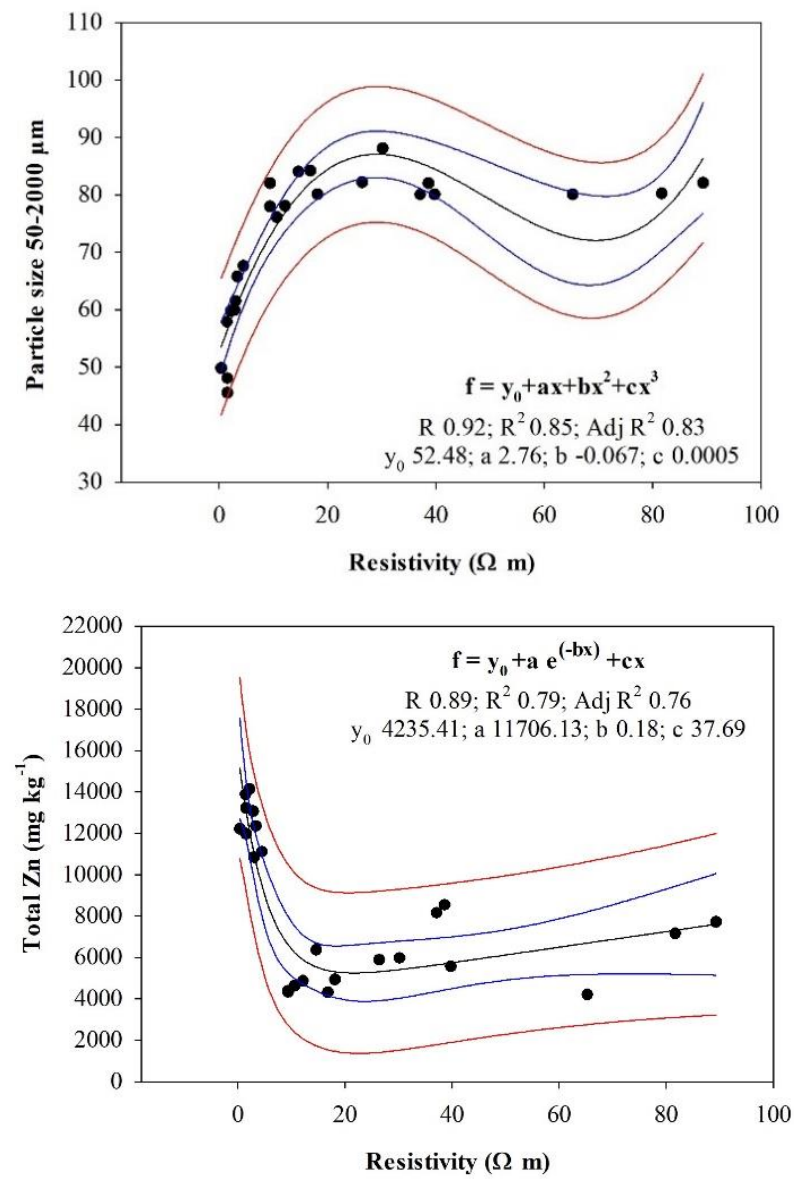
Minerals: Technology and Advances
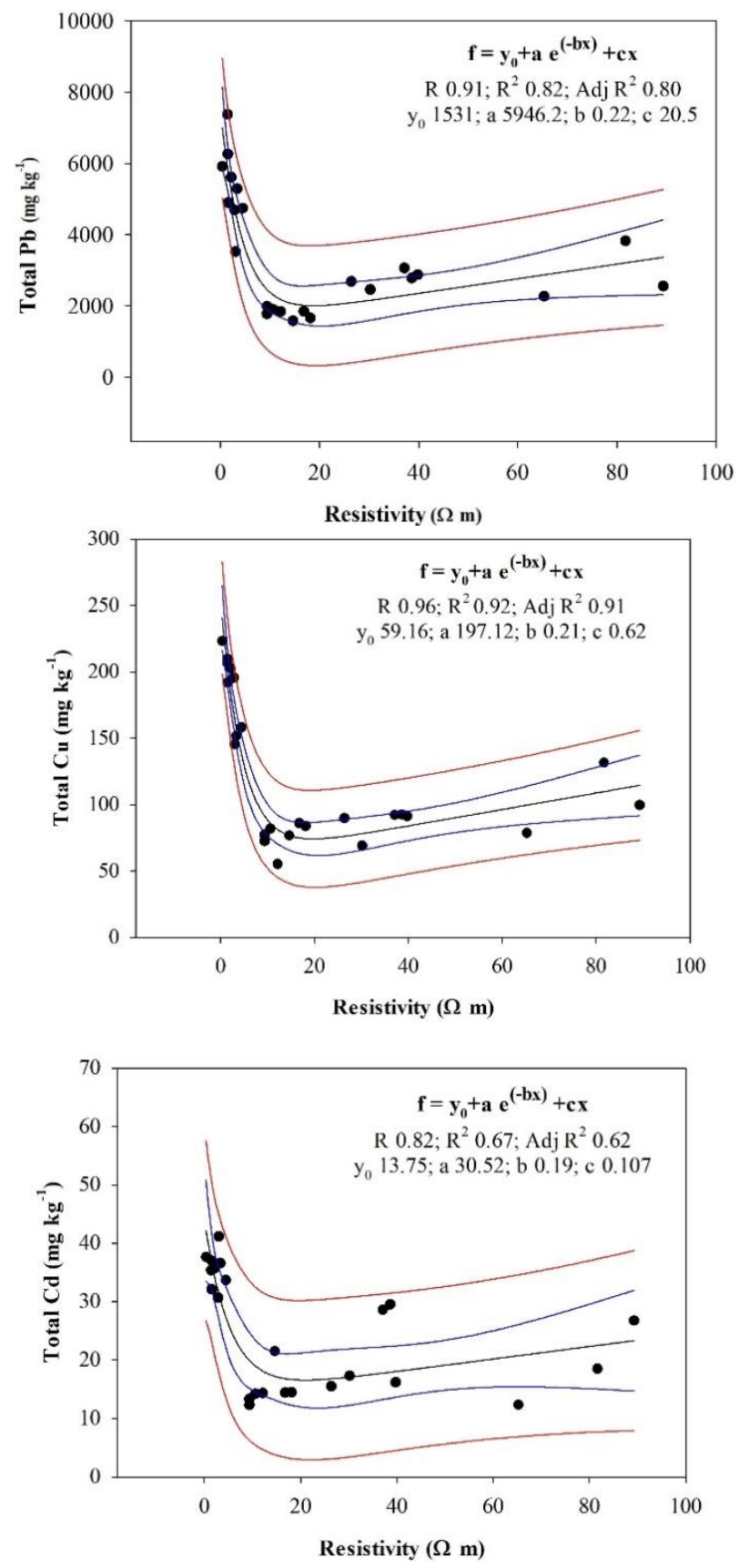
Minerals: Technology and Advances
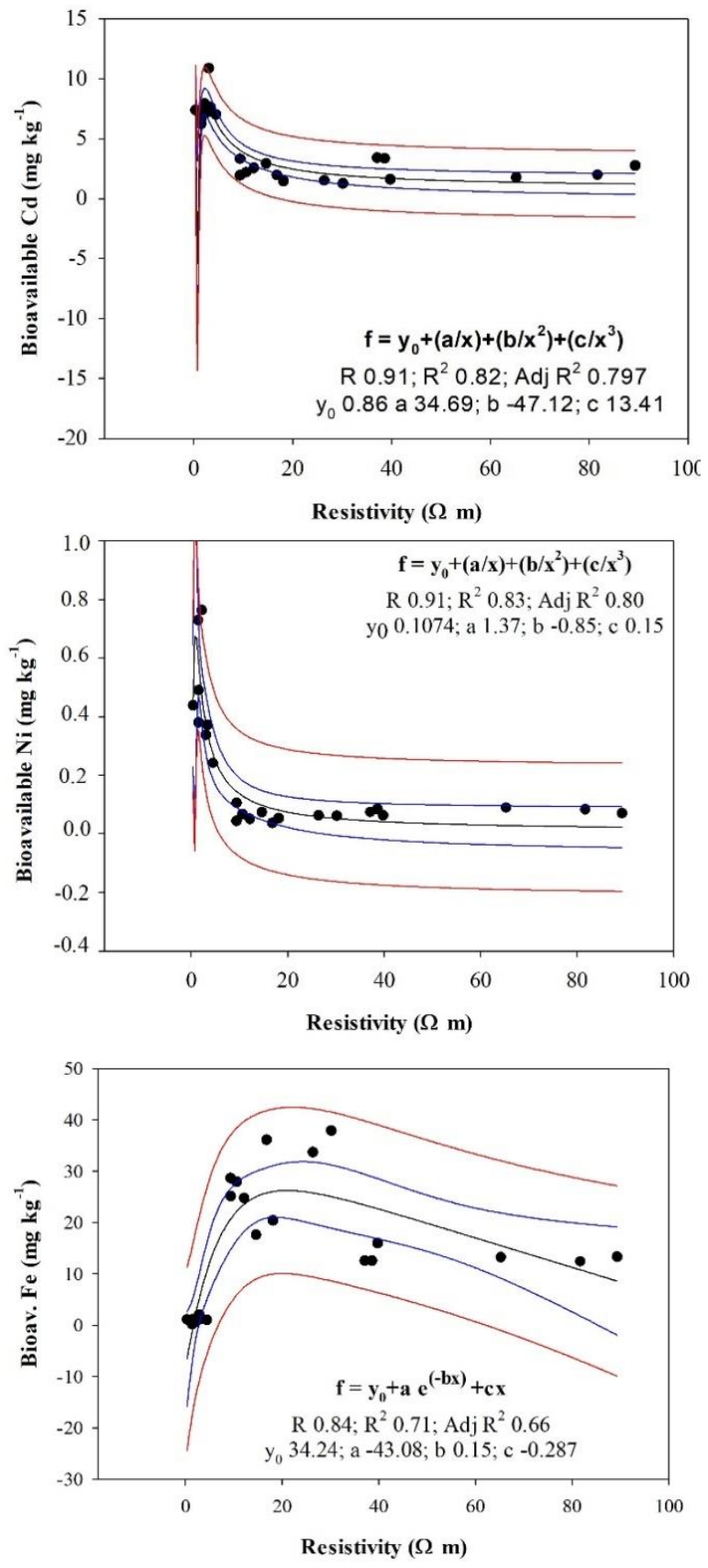
Minerals: Technology and Advances
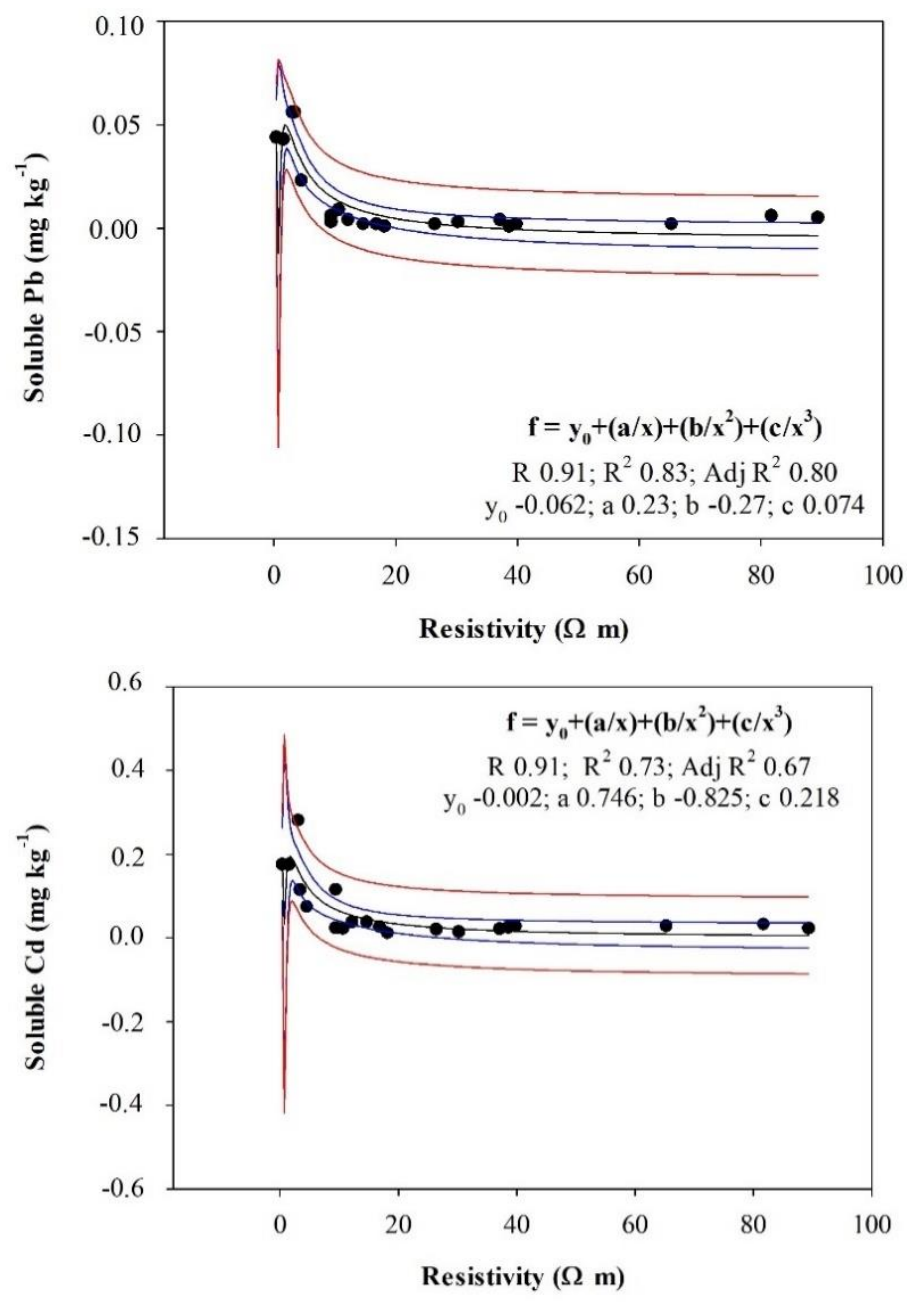

95\% Confidence Band

95\% Prediction Band

Figure 6: Calibrated model for soil properties and metal concentration estimation using resistivity as an explanatory variable $(n=24)$.

\section{Conclusions}

The geochemical characterization showed that metal concentrations, especially for $\mathrm{Zn}, \mathrm{Pb}$, and $\mathrm{Cd}$, in the surface area of the El Gorguel tailing pond exceed the legal reference level, 
with $\mathrm{Cd}$ being the most available and water-soluble metal in the pond, especially in the G1 area.

The ERT method has been a useful tool for supporting geochemical surveys for identifying subareas with different materials within tailing ponds. Thus, a high resistivity region was depicted on the surface of G2 and G3, and the G1 materials were catalogued as non-resistive.

By using the statistical model proposed, we estimated significant relations with soil electrical conductivity, bioavailable $\mathrm{Cd}$, medium and coarse particle sizes, total $\mathrm{Zn}$ and $\mathrm{Cd}$, and bioavailable $\mathrm{Ni}$ and $\mathrm{Fe}$, which allow for a cheaper and efficient way of estimating their concentration ranges in other similar tailing ponds of the Cartagena-La Unión mining district using values of resistivity. Plants species typically used in the phytoremediation of tailing ponds in Mediterranean semiarid climates rarely have very deep roots, so the geochemical state of the material from the surface to a 1 m depth needs to be known.

Thus, ERT can also serve as a proxy for the estimation of ranges of waste properties, because of the relationships observed primarily among the fine particle size distribution and the water retention with low values of electrical resistivity and, to a lesser extent, with the high metal concentration and solubility of the materials infilling the pond. It should be pointed that the relations established between metals and resistivity could be a consequence of the relation between the behavior of metals and the variation in particle size and moisture. Hence, the whole relation should be further studied for applications outside this mining district.

Although the correlations established in this study could be useful for revealing the location and distribution of the highest ranges of metal accumulation at this depth, which helps to avoid hard and expensive field surveys by reducing the number of boreholes and soil samples that need to be collected for physicochemical analysis, such surveys will remain essential for the quantitation and verification of the physicochemical 
properties of new tailing ponds and will never be replaced by any geophysical technique.

\section{References}

1. Thornton I. Impacts of mining on the environment, some local, regional and global issues. Applied Geochemistry. 1996; 11: 355-361.

2. Martín-Crespo T, Gómez-Ortiz D, Martín-Velázquez S, Esbrí JM, De Ignacio-San José C, et al. Abandoned mine tailings in cultural itineraries: Don Quixote Route (Spain). Engineering Geology. 2015; 197: 82-93.

3. Gómez-Ortiz D, Martín-Velázquez S, Martín-Crespo T, De Ignacio-San José C, Lillo J. Application of electrical resistivity tomography to the environmental characterization of abandoned massive sulphide mine ponds (Iberian Pyrite Belt, SW Spain). Near Surface Geophysics. 2010; 8: 65-74.

4. Kabas S, Faz A, Acosta JA, Zornoza R, Martínez-Martínez $\mathrm{S}$, et al. Effect of marble waste and pig slurry on the growth of native vegetation and heavy metal mobility in a mine tailing pond. Journal of Geochemical Exploration. 2012; 123: 69-76.

5. Zornoza R, Faz A, Carmona DM, Martínez-Martínez S, Acosta JA. Plant cover and soil biochemical properties in a mine tailing pond five years after application of marble wastes and organic amendments. Pedosphere. 2012; 22: 2232.

6. Martinez-Pagan P, Cano AF, Aracil E, Arocena JM. Electrical resistivity imaging revealed the spatial properties of mine tailing ponds in the Sierra Minera of southeast Spain. Journal of Environmental and Engineering Geophysics. 2009; 14: 63-76.

7. Cortada U, Martínez J, Rey J, Hidalgo MC, Sandoval S. Assessment of tailing pond seals using geophysical and hydrochemical techniques. Engineering Geology. 2017; 223: 59-70.

8. Conesa HM, Faz A, Arnaldos R. Initial studies for the phytostabilization of a mine tailing from the Cartagena-La Union Mining District (SE Spain). Chemosphere. 2007; 66: $38-44$. 
9. Parra A, Faz A, Zornoza R, Conesa E, Gómez-López MD. Heavy metal accumulation and tolerance in spontaneous vegetation in El Avenque dry river bed, southeast of Spain. In Proceedings Tailings and Mine Waste Vancouver, British Columbia, Canada: University of British Columbia. 2012; 445-450.

10. Norland MR, Veith DL. Revegetation of coarse taconite iron ore tailing using municipal solid waste compost. Selected papers presented at the Conference on Hazardous Waste Remediation. 1995; 41: 123-134.

11. Acosta JA, Martínez-Pagán P, Martínez-Martínez S, Faz A, Zornoza R, et al. Assessment of environmental risk of reclaimed mining ponds using geophysics and geochemical techniques. Journal of Geochemical Exploration. 2014; 147: 80-90.

12. Martín-Crespo T, Gómez-Ortiz D, Martín-Velázquez $\mathrm{S}$, Martínez-Pagán P, De Ignacio C, et al. Geoenvironmental characterization of unstable abandoned mine tailings combining geophysical and geochemical methods (Cartagena-La Union district, Spain). Engineering Geology. 2018; 232: 135-146.

13. Loke MH, Chambers JE, Rucker DF, Kuras O, Wilkinson PB. Recent developments in the direct-current geoelectrical imaging method. Journal of Applied Geophysics. 2013; 95: $135-156$.

14. Reynolds JM. An Introduction to applied and environmental geophysics. Oxford: Wiley-Blackwell (ed). 2011.

15. Rucker DF, Loke MH, Levitt MT, Noonan GE. Electricalresistivity characterization of an industrial site using long electrodes. Geophysics. 2010; 75: 95-104.

16. Rosales RM, Martinez-Pagan P, Faz A, Monero-Cornejo J. Environmental monitoring using electrical resistivity tomography (ERT) in the subsoil of three former petrol stations in SE of Spain. Water Air Soil Pollut. 2012; 223: 3757-3773.

17. Rosales RM, Martínez-Pagán P, Faz A. Bech, J. Study of subsoil in former petrol stations in SE of Spain: Physicochemical characterization and hydrocarbon contamination assessment. Journal of Geochemical Exploration. 2014; 147: 306-320. 
18. Martín-Crespo T, Gómez-Ortiz D, Martínez-Pagán P, De Ignacio-San José $\mathrm{C}$, Martín-Velázquez $\mathrm{S}$, et al. Geoenvironmental characterization of riverbeds affected by mine tailings in the Mazarrón district (Spain). Journal of Geochemical Exploration. 2012; 119-120: 6-16.

19. Vásconez-Maza MD, Martínez-Segura MA, Bueso MC, Faz Á, García-Nieto MC, et al. Predicting spatial distribution of heavy metals in an abandoned phosphogypsum pond combining geochemistry, electrical resistivity tomography and statistical methods. Journal of Hazardous Materials. 2019; 374: 392-400.

20. Page LM. Use of the electrical resistivity method for investigating geologic and hydrologic conditions in Santa Clara County, California. Groundwater. 1968; 6: 31-40.

21. Wilson SR, Ingham M, McConchie JA. The applicability of earth resistivity methods for saline interface definition. Journal of Hydrology. 2006; 316: 301-312.

22. Griffiths DH, Barker RD. Electrical imaging in archaeology. Journal of Archaeological Science. 1994; 21: 153-158.

23. Simyrdanis K, Papadopoulos N, Kim JH, Tsourlos P, Moffat I. Archaeological investigations in the shallow seawater environment with electrical resistivity tomography. Near Surface Geophysics. 2015; 13: 601-611.

24. White RMS, Collins S, Denne R, Hee R, Brown P. A new survey design for 3D IP inversion modelling at Copper Hill. Exploration Geophysics. 2001; 32: 152-155.

25. Bauman P. 2-D resistivity surveying for hydrocarbons - A primer. CSEG Recorder. 2005; 30: 25-33.

26. Legault JM, Carriere D, Petrie L. Synthetic model testing and distributed acquisition de resistivity results over an unconformity uranium target from the Athabasca Basin, northern Saskatchewan. The Leading Edge. 2008; 27: 46-51.

27. Linderholm P, Marescot L, Loke MH, Renaud P. Cell culture imaging using microimpedance tomography. IEEE Transactions on Biomedical Engineering. 2008; 55: 138146.

28. Storz H, Storz W, Jacobs F. Electrical resistivity tomography to investigate geological structures of the earth's upper crust. Geophysical prospecting. 2000; 48: 455-471. 
29. Martínez-Pagán P, Faz A, Acosta JA, Carmona DM, Martínez-Martínez S. A multidisciplinary study for mining landscape reclamation: A study case on two tailing ponds in the Region of Murcia (SE Spain). Physics and Chemistry of the Earth. 2011; 36: 1331-1344.

30. Lghoul M, Teixido T, Peña JA, Hakkou R, Kchikach A, et al. Electrical and seismic tomography used to image the structure of a tailings pond at the abandoned Kettara mine, Morocco. Mine Water Environ. 2012; 31: 53-61.

31. Matys Grygar T, Elznicová J, Tůmová Š, Faměra M, Balogh $\mathrm{M}$, et al. Floodplain architecture of an actively meandering river (the Ploučnice River, the Czech Republic) as revealed by the distribution of pollution and electrical resistivity tomography. Geomorphology. 2016; 254: 41-56.

32. Michot D, Benderitter Y, Dorigny A, Nicoullaud B, King D, et al. Spatial and temporal monitoring of soil water content with an irrigated corn crop cover using surface electrical resistivity tomography. Water Resour Res. 2003; 39: 1138.

33. Brevik EC, Fenton TE, Lazari A. Soil electrical conductivity as a function of soil water content and implications for soil mapping. Precis. Agric. 2006; 7: 393-404.

34. Brunet P, Clément R, Bouvier C. Monitoring soil water content and deficit using electrical resistivity tomography (ERT) - A case study in the Cevennes area, France. J. Hydrol. 2010; 380: 146-153.

35. Kotková K, Nováková T, Tůmová S, Kiss T, Popelka J, et al. Migration of risk elements within the floodplain of the Litavka River, the Czech Republic. Geomorphology. 2019; 329: 46-57.

36. Hadzick ZZ, Guber AK, Pachepsky YA, Hill RL. Pedotransfer functions in soil electrical resistivity estimation. Geoderma. 2011; 164: 195-202.

37. Martínez-Martínez S, Acosta JA, Faz-Cano A, Carmona DM, Zornoza R, et al. Assessment of the lead and zinc contents in natural soils and tailing ponds from the Cartagena-La Unión mining district, SE Spain. Journal of Geochemical Exploration. 2013; 124: 166-175.

38. AEMET. 2019. Available online at : http://www.aemet.es/es/serviciosclimaticos/datosclimatologi $\underline{\cos / \text { valoresclimatologicos? }=7031 \& \mathrm{k}=\text { mur }}$ 
39. Acosta JA, Faz A, Martínez-Martínez S, Zornoza R, Carmona DM, et al. Multivariate statistical and GIS-based approach to evaluate heavy metals behavior in mine sites for future reclamation. Journal of Geochemical Exploration. 2011; 109: 1-3, 8-17.

40. Acosta JA, Abbaspour A, Martínez GR, Martínez-Martínez $\mathrm{S}$, Zornoza R, et al. Phytoremediation of mine tailings with Atriplex halimus and organic/inorganic amendments: A fiveyear field case study. Chemosphere. 2018; 204: 71-78.

41. Spitz K, Trudinger J. Mining and the Environment: From Ore to Metal. 2008; 812.

42. Australian National Committee on Large Dams (ANCOLD). Guidelines on tailings dam design, construction and operation. 1999. Available Online at: http://www.ancold.org.au

43. Butler DK. Near-Surface Geophysics. Society of Exploration Geophysicists, Tulsa, Oklahoma, U.S.A. 2005; 758.

44. Dahlin T, Zhou B. A numerical comparison of 2D resistivity imaging with 10 electrode arrays. Geophysical Prospecting. 2004; 52: 379-398.

45. Martorana R, Capizzi P, D’Alessandro A, Luzio D. Comparison of different sets of array configurations for multichannel 2D ERT acquisition. Journal of Applied Geophysics. 2017; 137: 34-48.

46. Bernard J. Short note on the depth of investigation of electrical methods: IRIS Instruments. Orleans, France. 2003; 8. Available Online at: Available in: http://www.irisinstruments.com

47. Loke MH. Tutorial: 2-D and 3-D electrical imaging surveys. Geotomosoft. 2015. Available Online at:

http://www.geotomosoft.com

48. Loke MH, Barker RD. Rapid least $\square$ squares inversion of apparent resistivity pseudosections by a quasi $\square$ Newton method. Geophysical Prospecting. 1996; 44: 131-152.

49. Loke MH, Acworth I, Dahlin T. A comparison of smooth and blocky inversion method in 2D electrical imaging surveys. Explor Geophys. 2003; 34: 182-187.

50. Martínez Pagán P. Aplicación de diferentes técnicas no destructivas de prospección geofísica a problemas relacionados con contaminación ambiental producida por 
diferentes actividades antrópicas en la Región de Murcia [Application of different non-invasive geophysical prospecting methods to problems related to environmental contamination caused by anthropical activities in the Region of Murcia (Spain)] (Doctoral thesis). 2006.

51. Soil Survey Staff. Soil survey laboratory methods manual. Version no. 4.0. USDA NRCS. Soil Survey Investigations Report No. 42. U.S. Govt. Print. Office, Washington D.C. 2004.

52. Dewis J, Freitas F. Physical and chemical methods of soil and water analyses. Soils Bulletin (FAO) $N^{\circ} 10$. Roma: FAO. 1970.

53. Risser JA, Baker DE. Testing soils for toxic metals. In: RL Westerman, editor. Soil Testing and Plant Analysis. Soil Science Society of America. Special Publication 3.3rd Ed. Madison. 1990; 275-298.

54. Lindsay WL, Norvell WA. Development of a DTPA soil test for $\mathrm{Zn}, \mathrm{Fe}, \mathrm{Mn}$, and $\mathrm{Cu}$. Soil Science Society of America Journal. 1978; 42: 421-428.

55. Crock JG, Severson RC. Four reference soil and rock samples for measuring element availability in the western energy regions. U.S. Geological Survey Circular. 1980; 841: 16.

56. Buurman P, van Lagen B, Veltorst EJ. Manual for Soil and Water Analysis. Netherlands: Backhuys publishers, Technical report. 1996.

57. Frau F. The formation-dissolution-precipitation cycle of melanterite at the abandoned pyrite mine of Genna Luas in Sardinia, Italy: environmental implications. Mineralogical Magazine. 2000; 64: 995-1006.

58. Sobek AA, Schuller WA, Freeman JR, Smith RM. Field and Laboratory Methods Applicable to Overburdens and Mine Soils. EPA-600/2-78-054. 1978.

59. Zornoza R, Faz A, Martínez-Martínez S, Acosta JA, Constantini R, et al. In: AA Ansari, editors. Suitability of Different Mediterranean Plants for Phytoremediation of Mine Soils Affected with Cadmium. Switzerland: Springer International Publishing. 2016. Phytoremediation. 2016.

60. Martínez-Sánchez MJ, Pérez-Sirvent C. Niveles de fondo y niveles genéricos de referencia de metales pesados en suelos 
de la Región de Murcia. Secretaria autonómica para la sostenibilidad. Dirección General de Calidad Ambiental y Universidad de Murcia. 2007.

61. WHO (World Health Organization), Ten chemicals of major public health concern in International Programme on Chemical Safety, 2019. Available Online at: https://www.who.int/ipcs/assessment/public_health/chemical s phc/en/

62. Perez-Sirvent C, Hernandez-Perez C, Martinez-Sanchez MJ, Garcia-Lorenzo ML, Bech J. Geochemical characterisation of surface waters, topsoils and efflorescences in a historic metal-mining area in Spain. J Soils Sediments. 2016; 16: $1238-1252$.

63. Gabarron M, Faz A, Acosta JA. Use of multivariable and redundancy analysis to assess the behavior of metals and arsenic in urban soil and road dust affected by metallic mining as a base for risk assessment. Journal of Environmental Management. 2018; 206: 192-201.

64. Paillet Y, Cassagne N, Brun JJ. Monitoring forest soil properties with electrical resistivity. Biol Fertil Soils. 2010; 46: 451-460.

65. Maloteau S, Blanchy G, Javaux M, Garré S. Influence of plant roots on electrical resistivity measurements of cultivated soil columns. Geophysical Research Abstracts. Vol. 18, EGU2016-11695, 2016. EGU General Assembly. 2016

66. Acosta JA, Faz A, Martínez P, Martínez-Martínez S, Muñoz MA, et al. Environmental Risk Assessment of Tailings Ponds Using Geophysical and Geochemical Techniques. Assessment. In Restoration and Reclamation of Mining Influenced Soils. New York: Elsevier Inc. 2017; 135-148.

67. Styles P. Environmental Geophysics. Everything you ever wanted (needed!) to know but were afraid to ask! (Vol. 7). Houten, The Netherlands: European Association of Geoscientists and Engineers. 2012. Available Online at: https://bookshop.eage.org/book-author/peter-styles/

68. Samouëlian A, Cousin I, Tabbagh A, Bruand A, Richard G. Electrical resistivity survey in soil science: a review. Soil \&Tillage Research. 2005; 83: 173-193. 
69. Faz A, Acosta JA, Martínez-Martínez S, Martínez-Pagán P, Carmona DM, et al. Risk assessment for the environment, population and infrastructures of some abandoned tailing ponds in the mining district of Cartagena-La Union (SE Spain). In Metal Contamination: Sources, Detection and Environmental Impact. 2013; 194-217.

70. Kong S, Lu B, Ji Y, Zhao X, Chen L, et al. Levels, risk assessment and sources of PM10 fraction heavy metals in four types dust from a coal-based city. Microchem. J. 2011; 98: 280-290.

71. Lu S, Feng M, Yao Z, Jing A, Yufang $Z$, et al. Physicochemical characterization and cytotoxicity of ambient coarse, fine, and ultrafine particulate matters in Shanghai atmosphere. Atmos. Environ. 2011; 45: 736-744.

72. Yurkevich N, Bortnikova S, Olenchenko V, Abrosimova N, Saeva O, et al. Study of Water-rock Interaction in Sulfide Mining Tailings using Geochemical and Geoelectrical Methods. 15th Water-Rock Interaction International Symposium, WRI-15. Procedia Earth and Planetary Science. 2017; 17: 112-115.

73. Placencia-Gómez E, Parviainen A, Hokkanen T, LoukolaRuskeeniemi K. Integrated geophysical and geochemical study on AMD generation at the Haveri $\mathrm{Au}-\mathrm{Cu}$ mine tailings, SW Finland. Environ Earth Sci. 2010; 61: 14351447.

74. Alamry AS, van der Meijdeb M, Noomenb M, Addinkc EA, van Benthemc R, et al. Spatial and temporal monitoring of soil moisture using surface electrical resistivity tomography in Mediterranean soils. Catena, 2017, 157, 388-396.Werban, U., Kuka, K., Merbach, I. Correlation of electrical resistivity, electrical conductivity and soil parameters at a long-term fertilization experiment. Near Surface Geophysics. 20091 514.

75. Hooda PS. Trace Elements in Soils. New Jersey: Blackwell Publishing Ltd. 2010. 